Correction

\title{
Correction: Arshad A.; et al. An Analysis of Photo-Voltaic Hosting Capacity in Finnish Low Voltage Distribution Networks. Energies 2017, 10, 1702
}

\author{
Ammar Arshad* (D), Martin Lindner and Matti Lehtonen \\ Department of Electrical Engineering and Automation, Aalto University, Maarintie 8, 02150 Espoo, Finland; \\ aalto@mlindner.eu (M.L.); matti.lehtonen@aalto.fi (M.L.) \\ * Correspondence: ammar.arshad@aalto.fi; Tel.: +358-469-679-949
}

Received: 1 February 2018; Accepted: 12 March 2018; Published: 20 March 2018

The authors would like to correct following errors: In Table 6, E7 is to be changed to E4 in the second row, last column. The table is located on Page 9 [1]. The correct expressions are given as:

Table 6. Test Networks' mean HCs and their limiting constraints.

\begin{tabular}{cccccc}
\hline & \multicolumn{2}{c}{ Balanced (3-Phase) } & \multicolumn{2}{c}{ Unbalanced (1-Phase) } \\
\hline Region & MV Drop & $\mu_{H C}(\%)$ & Limiting Constraint & $\mu_{H C}(\%)$ & Limiting Constraint \\
\hline \multirow{2}{*}{ PR } & $-5 \%$ & 279.2 & E7 & 155.9 & E7,E4 \\
& $0 \%$ & 198.1 & E3,E7 & 128.9 & E4,E7 \\
& $5 \%$ & 117.2 & E3 & 87.7 & E3 \\
\hline \multirow{2}{*}{ IN } & $-5 \%$ & 273.9 & E7 & 156.3 & E4 \\
& $0 \%$ & 233.5 & E7 & 117.4 & E4 \\
& $5 \%$ & 154.6 & E3,E7 & 98.2 & E3,E4 \\
PU & $-5 \%$ & 246.4 & E5,E7 & 95.9 & E4,E6 \\
& $0 \%$ & 239.7 & E5,E7 & 95.4 & E6,E4 \\
& $5 \%$ & 242.5 & E5,E7 & 86.8 & E3,E6
\end{tabular}

Moreover, on page 10 the paragraph describing table 6 findings, also requires one line change. The correct expressions are given as "For the IN region, the constraints of E4 ( $-5 \%$ and $0 \%$ MV changes) and E3 (+5\% MV rise case) were violated." Instead of "For the IN region for all MV values, the same constraints of E3 and E7 were violated as in the balanced feed-in scenario."

The manuscript will be updated, and the original one will remain available on the article webpage.

\section{Reference}

1. Arshad, A.; Lindner, M.; Lehtonen, M. An Analysis of Photo-Voltaic Hosting Capacity in Finnish Low Voltage Distribution Networks. Energies 2017, 10, 1702. [CrossRef]

(c) 2018 by the authors. Licensee MDPI, Basel, Switzerland. This article is an open access article distributed under the terms and conditions of the Creative Commons Attribution (CC BY) license (http:// creativecommons.org/licenses/by/4.0/). 